\title{
Reutilización del desperdicio de frutas para el aprovechamiento en nuevas fibras
}

\section{Re-use of fruit waste to produce new fibers}

\author{
Lizbet Condor ${ }^{1}$, Heidy Choque ${ }^{1}$, Natali Miranda ${ }^{1}$ \\ ${ }^{1}$ E.A.P Ing Textil y Confecciones Universidad Nacional Mayor de San Marcos, Calle Germán Amézaga Nro 375,Lima-Peru \\ Recibido : 30/05/2017 Aceptado: 14/08/2017
}

\section{RESUMEN}

El presente trabajo de investigación busca enfrentar la problemática actual en referencia al desperdicio en crecimiento de alimentos perecibles ocasionados por deficiencias en la distribución debido a los diversos percances en las rutas de transporte desde las provincias hasta la capital, que es el principal mercado para los agricultores y comerciantes dentro del país. Con el análisis de determinadas frutas seleccionadas en un alto estado de maduración se demostrará características y utilidades de la reutilización de estas en referencia al reemplazo del cuero, generando un producto sostenible y económico.

Palabras Clave: frutas, reutilización, cuero, sostenible.

\section{ABSTRACT}

This research seeks to address the current problem in reference to the growing waste of perishable foodstuffs caused by deficiencies in distribution due to the various mishaps on the transport routes from the provinces to the capital, which is the main market for farmers. With the analysis of selected fruits, characteristics and uses of the reuse of these will be demonstrated in reference to the replacement of leather, generating a sustainable and economic product.

Palabras Clave: Fruits, reuse, leather, sustainable

\section{INTRODUCCIÓN}

A diario hay un gran desperdicio de frutas y verduras malogradas que son desechadas por los comerciantes de diversos mercados, si nos preguntamos ¿A dónde irán estos desperdicios?, pues a la basura; que originan malos olores e incluso pueden dañar la salud de las personas que transitan por ahí ya que la basura en nuestra capital no está del todo controlada, pero vamos a enfocarnos más en la basura a base de frutas y verduras malogradas.

Se desechan alrededor de 30 mil toneladas de basura en el mercado mayorista de Santa Anita (ex Parada); entre estos desechos podemos rescatar los vegetales, frutas podridas y desperdicios de los mismos para crear un material biodegradable parecido al cuero u otros productos como tela para bolsos; de esta manera así poder aligerar la carga de basura diaria que se produce en los mercados, sin contar con el gran apoyo ecológico que la sociedad podría aportar al hacer uso de prendas o accesorios de estos materiales.

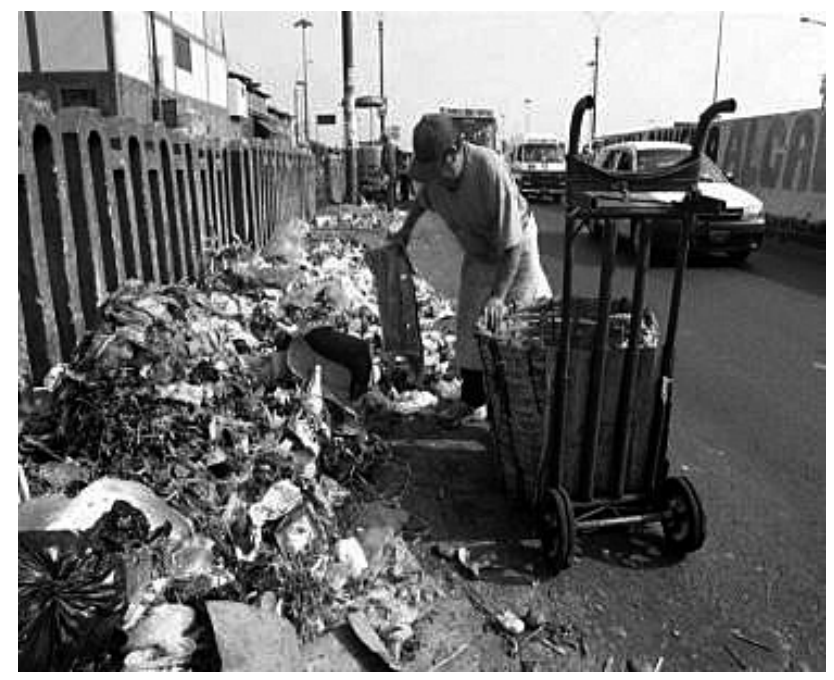

Figura 1: Fuentes: diario El comercio. 2016 _Caqueta, Lima 


\section{PROBLEMÁTICA}

Las personas en situación de inseguridad alimentaria alcanzan en el Perú a 2.3 millones y en el caso de Lima y Callao son más de 320 mil. El desperdicio de alimento es muy elevado según las estimaciones de la FAO indica que cerca de 7 millones de toneladas de alimentos son destruidos cada año a nivel nacional. Sin contar con los perjuicios a la salud que esto conlleva, la aglomeración de desperdicios no solo tiene que ver con la sobreproducción si con la situación en la que llega la fruta desde provincia, también que, Perú no cuenta con unas carreteras óptimas para el transporte del mismo sino que también a esta problemática se le suma las diversas ocasiones en la que la naturaleza ha azotado al país con fenómenos naturales. Entonces a base de estos datos alarmantes se ha encontrado una manera de lidiar con esto, ¿Se podrá realizar un proyecto a base de frutas, que resuelvan esta problemática?.

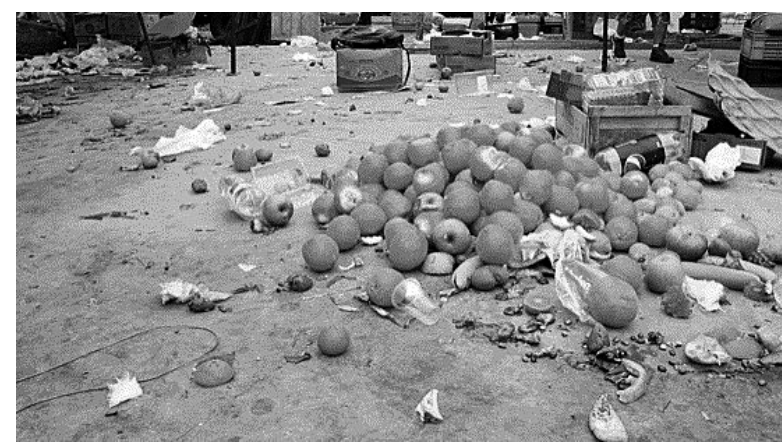

Figura 2: Millones de frutas son desechadas cada día por el mercado mayorista. Fuentes: Foro Libre por Zhack, 25 marzo 2013

\subsection{Prueba experimental}

Tras ver la gran cantidad de basura orgánica que desecha los mercados, se planteó reusarla, la fruta peruana que ya no sirve y así también sus desechos (como hojas o cáscaras) debe volver a ser revalorada dándole un nuevo significado, un valor agregado "sostenible" y "biodegradable" pero ¿Como hacer?, ¿Como empezar? esas fueron unas de las primeras preguntas. Se realizó mucho estudio de mercado queriendo tomar un ejemplo digno de nuestros principios ecológicos y tratando de no sobrepasar la valla de "imitación de producto", recientemente estudiantes holandeses notaron la misma problemática en su pueblo natal y la idea surgió de pronto en nosotros dándole un enfoque no solo lucrativo, sino social; ya que esto más que beneficiar a los estudiantes propiamente se trata de beneficiar a los comerciantes de fruta ya que con el impacto de los fenómenos que acontecen en nuestro país, ellos son los más perjudicados en lo que se refiere a pérdida de producto. Actualmente en el mercado los productos de este tipo tienen una durabilidad de 3 meses siendo posteriormente su inicio de pérdida de valor, lo cual es lo más comprometedor ya que nos lleva a variar en los modelos que se pueden realizar de este material.

Se realizó en pequeña escala de manera casera probando diferentes insumos, para evaluar la dificultad del proceso, y que tan rentable podría ser para aplicarla en mayores proporciones.

Los materiales usados fueron frutas como el mango, papaya y melón en un alto grado de maduración, y también los desechos o residuos que se usaron tales como hojas o tallos que no se consumen y se desecha como basura se obtuvieron de plátano y piña.

La problemática en cifras
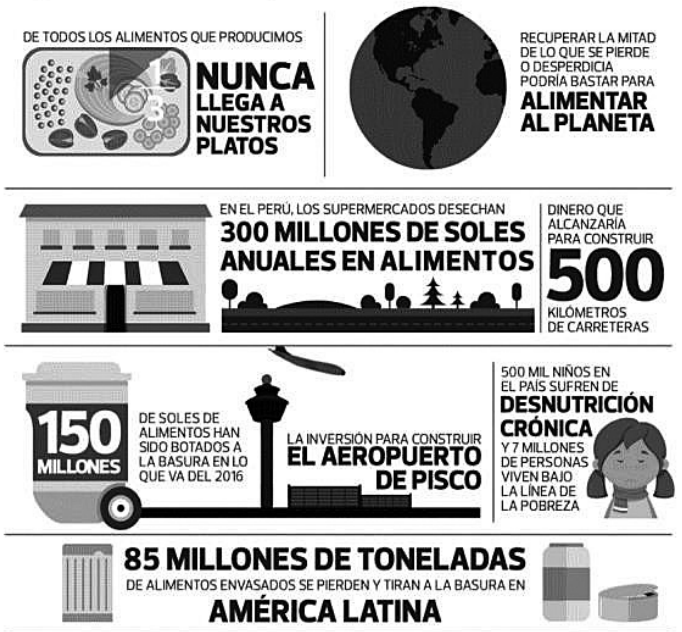

Figura 3: Fuente: FAO_COMEXPERU extraído del INEI

2.1.1. Fibra para carteras a base de mango u otras frutas

\section{Materiales}

- Mango u otras frutas en alto grado de maduración

- Cuchillo

- Horno o extractor de humedad

- Bandeja de acero

- Tijeras

- Recipientes

- Moldes

Primer paso: la separación física de las partes de la fruta se realiza de forma manual o con la ayuda de un cuchillo afilado.

Segundo paso: retiramos las semillas de la fruta en un alto grado de maduración. Las partes por separado se pesan en gramos.

Tercer paso: nos disponemos a triturar la fruta, hasta obtener una masa con ella, que sea consistente y homogénea. 
Cuarto paso: ahora lo vamos a llevar a su punto de ebullición para detener el proceso de descomposición, paso importante para evitar los posibles olores fuertes del mismo.

Quinto paso: colocamos la masa extendiéndose sobre una superficie plana y luego la colocamos en el horno durante 3 horas para que se compacte y pierda la humedad inicial.

\section{Beneficios de realizar carteras de frutos en estado putrefacto}

Además del problema de los residuos de alimentos, la producción de cuero animal es también un problema ambiental. El impacto es mayor entre las regiones más pobres y menos desarrollados del mundo. Cada año, más de mil millones de animales son sacrificados para que se puedan utilizar sus pieles. El proceso de limpieza a lo que se someten los cueros a producir en el mundo es aproximadamente 650 millones de kilos de $\mathrm{CO}_{2}$. Además, que se sabe que el $10 \%$ de los gases de efecto invernadero lo ocasiona los frutos en estado de putrefacción y esta solución alternativa podría reducir en gran medida estos efectos.

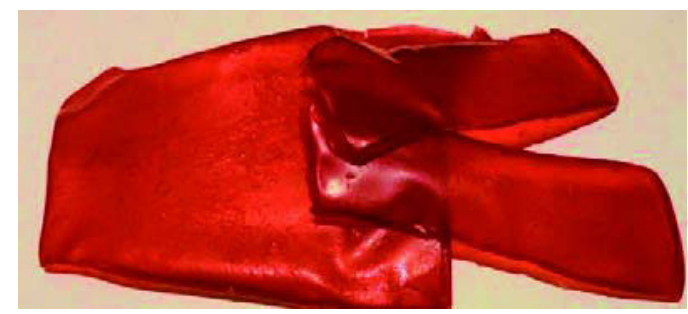

Figura 4: Al Realizar el experimento de manera casera notamos la rigidez de este material, efectivamente tiene una similitud al cuero animal

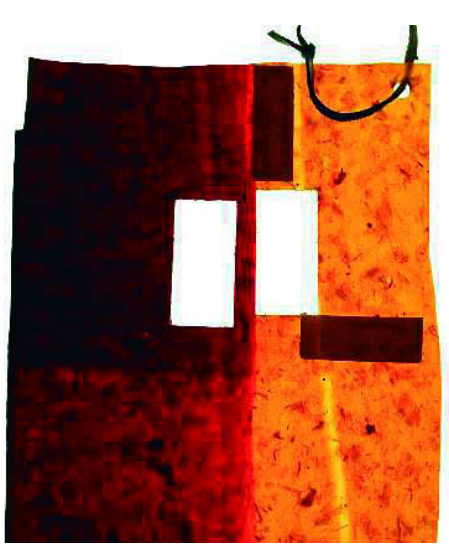

Figura 5: Láminas de diferentes contexturas del cuero de mango

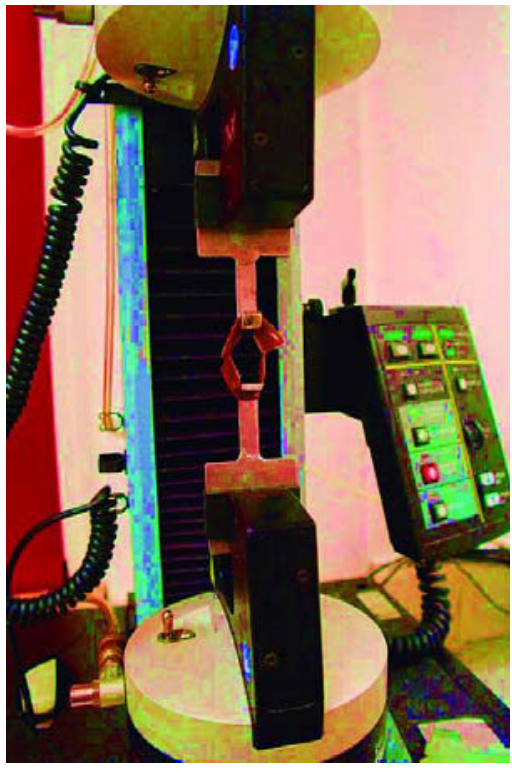

Figura 6: Examen de resistencia de la fibra

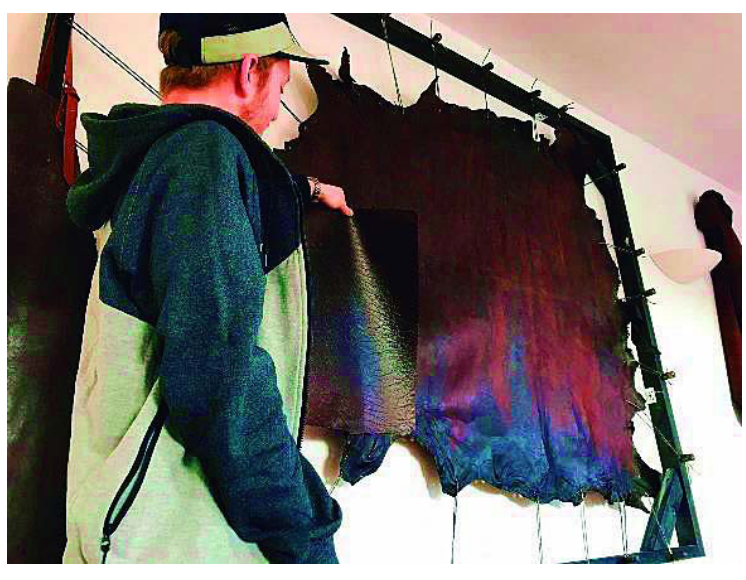

Figura 7: Tendido para secar

\subsubsection{Porta vasos a base de piña o plátano}

\section{Materiales}

Cuando la piña se comercializada se le retira la parte superior que contiene sus hojas, si bien, estas con pequeñas, se puede obtener de ellas fibra muy fácilmente. De igual manera con el plátano; cuando se comercializa el plátano llega con hojas de la planta y es de ahí donde se obtiene el provecho.

- Una cuchilla filosa

- Colorantes alimenticios

- Cualquier utensilio que permita tejer, ya sea (crochet, palitos de tejer)

- Tijeras

Primer paso: De las hojas de piña o plátano se raspa cuidadosamente para obtener las fibras, están 
salen con un poco de clorofila, pero se las elimina con agua, tratando de refregar sin maltratarlas.

Segundo paso: cuando tenemos la fibra seca se la tiñe con colorante alimenticio para darle el color que deseamos.

Tercer paso: después de teñir los hilos de piña o plátano se pasa a tejer de alguna manera, ya sea con palitos o manualmente.

\subsubsection{PROPIEDADES EN UN TEJIDO DE PIÑA}

Este tejido tiene el aspecto de cuero lo que hace muy atractivo a la vista, se puede asemejar en propiedades en el cuero animal, es un textil flexible, resistente, versátil, transpirable, suave y ligero se puede utilizar este producto como se mencionó en zapatos, bolsas, cintas y sombreros, sus usos se asemejan a la fibra de cáñamo o de yute.

Es muy rentable su extracción, por ejemplo, para producir un metro cuadrado de cuero de piña se necesitan solo 480 hojas, de 16 piñas y todo esto de sus residuos no propiamente de su alimento que, si se comercializa, lo cual la hace muy rentable.

Además, que lo que se deseche de esta extracción representa un $5 \%$ de la materia base, en contra de un $25 \%$ para el cuero animal. Los desechos de la materia vegetal se transforman en biogás y abono orgánico destinados a los agricultores locales, entre otros estudios realizados químicamente se estima la fabricación de este cuero contamina un $20 \%$ menos que la producción del cuero animal. En un costo proyectado se asume que el metro cuadrado de este producto orgánico cuesta 6 soles menos que el metro cuadrado de cuero anima, siendo el precio de este de 88 soles.

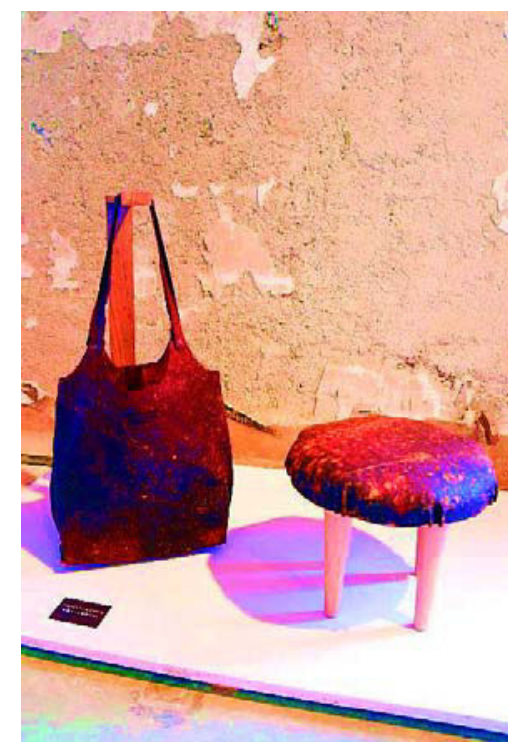

Figira 6: Se realizó carteras y asientos en un proceso es masa en Holanda, pudiendo notar la rentabilidad del proceso

\section{RESULTADOS}

\section{Con respecto al cuero de frutas:}

El material que se obtiene no presenta un olor fuerte pues este ha sido mitigado gracias al uso del colorante vegetal. La textura es diversa por la gran variedad de frutas que se trata.

El material es moldeable semejante al cuero

La durabilidad está en etapa de desarrollo

\section{Con respecto a la fibra de plátano y piña:}

Su obtención no es complicada ni trabajosa por lo que puede ser muy rentable, los campesinos de estos cultivos podrían tener un ingreso adicional, ya no solo basándose en el fruto sino en sus desperdicios.

La textura es como el cáñamo, y tiene las mismas aplicaciones, para tapetes, sombreros, carteras, etc.

Es resistente a la rotura.

La durabilidad está en etapa de desarrollo.

\section{CONCLUSIONES}

Por los resultados obtenidos se observa que este proyecto es una opción ecológica para evitar el desperdicio como contaminante ambiental, social por lo que la alternativa puede ser también rentable como ya lo hemos comprobado. También se pude manifestar que tiene potencial en nuestro país, ya que es inmensamente variado en el tema de productos naturales por su riquísima y fértil tierra; lejos de ser un perjuicio para los productores puede surgir una nueva forma de emprender y recabar mayores ingresos sin desperdiciar producto.

La sustitución del material textil cuero es posible, con la reutilización de estos residuos resultarnos un material mucho más económico y por los motivos ya antes mencionados amigable con el medio ambiente.

Perú es un país que debería aportar más en tecnología para su siguiente paso que es la industrialización; se requiere, según el análisis, de ideas emprendedoras que dirección en hacia adelante al país y los suyos; por ello, busca materiales alternativos en favor no solo de las necesidades del hombre sino también del cuidado del medio ambiente. 


\section{AGRADECIMIENTO}

Agradecemos en primera instancia al Coloquio por otorgarnos la oportunidad de impartir nuestras ideas emprendedoras. A nuestros padres por el tiempo y apoyo que nos brindaron para la elaboración experimental de los procesos y en fin de llegar a nuestro objetivo financiando ciertos materiales, a nuestros profesores por impartir en sus aulas la visión de ayuda social y protección al medio ambiente; siendo este, nuestro objetivo principal en el presente trabajo. Nuestro país debe ser un lugar más ecológico, si bien la tarea es ardua, los jóvenes tenemos la visión de superar los retos impuestos.

\section{REFERENCIAS BIBLIOGRÁFICA}

[1] Fruitlether Rotterdam (2015) http://fruitleather.nl/home/project/ (visitado el 2017-05-18)

[2] Laverde, M.(2012).Laboratorio de Fibras, http:// teffiles.blogspot.pe/2012/05/laboratorio-de-fibras- acetatofibra.html (visitado el 2017-04-28)

[3] Ananas ananam, news materials for a new world http://www.ananas-anam.com/pinatex/ (visitado 2017-05-10)

[4] Carmen Alvarez A. Hinojosa thesis Piñatex, The design development of a new sustainab̄le material http://researchonline.rca.ac.uk/1677/1/1.\%20CARMEN\%20T HESIS\%20FINAL\%202015\%20\%281\%29.pdf (visitado el 2017-05-16)

[5] Oxford academic https://academic.oup.com/jxb/article/58/5/ 1047/488428/Differ ential-feedback-regulation-of-ethylene (visitado el 2017-05-16)

[6] Universidad de filipinas piñatex (2013) Fibras Naturales http:// www.ideassonline.org/public/pdf/NaturalLeather-ESP.pdf (visitado el 2017-05-18)

[7] Blog by Dr ljad madish and Dr. Soren hofmagen 2008 Microscope study of fruit surface https://www.researchgate.net/figure/23987591_fig2_Figure -5-ESEM-images-of-E-coli-O157H7-cells-attached-to-fruitsurfaces-A-cantaloupe (visitado el 2017-05-18) 